\title{
Synthesis and Characterization of Thermally Resistant Coordination Polymers of Poly(sulphonediphenyleneterephthalamide)
}

\author{
Anjali BaJPaI, Sandeep RaI, ${ }^{*}$ and Udai Diwaker Nath BaJPaI* \\ Department of Chemistry, Government Autonomous Science College, \\ Jabalpur 482001 , India \\ * Polymer Research Laboratory, Department of Post Graduate Studies \\ and Research in Chemistry, Rani Durgavati University, \\ Jabalpur 482001 , India
}

(Received May 24, 1996)

\begin{abstract}
A series of Schiff's Base coordination polymers was prepared using amino group terminated oligomeric ligand poly(sulphonediphenyleneterephthalamide) (PSDTA) and $\mathrm{Co}(\mathrm{II}), \mathrm{Ni}(\mathrm{II})$, and $\mathrm{Cu}(\mathrm{II})$ complexes of salicylaldehyde $\left[\mathrm{M}(\mathrm{Sal})_{2}\right]$ and 2-hydroxy-1-napthaldehyde $\left[\mathrm{M}(\mathrm{Napthal})_{2}\right]$. The coordination polymers were characterised by IR spectroscopy, elemental analysis, magnetic susceptibility measurements, and thermogravimetric analysis (TGA). Oxygen and nitrogen coordinated structures of coordination polymers have been proposed on the basis of physico-chemical studies. Thermogravimetric analysis showed enhancement in the thermal stability of coordination polymers in comparison to the aramid ligand, PSDTA.

KEY WORDS Polyaramids / Coordination Polymers / Polymeric Schiff's Base Complexes / Heat Resistant Polymers / High-Performance Polymers / Metal Containing Polymers /
\end{abstract}

Aromatic polyamides, or polyaramides or aramids, have high melting points, high thermal stability and high performance properties. The production of aramids is somewhat difficult due to the low reactivity of aromatic amines. They have been synthesized by low temperature condensation which includes interfacial and solution polymerization techniques. Another important technique is the phosphorylation reaction reported by Yamazaki et $a l^{1,2}$ a useful and direct polycondensation method for the synthesis of a large number of aromatic polyamides. ${ }^{3}$ The mechanism involves the formation of an $\mathrm{N}$-phosphonium salt in the presence of pyridine. ${ }^{4}$ The polycondensation takes approximately $2.5 \mathrm{~h}$ for completion $^{5,6}$ and is affected by triphenylphosphite. The phosphorylation reaction is an easy and novel route for the synthesis of high as well as very low ${ }^{7}$ molecular weight polyaramids. Sreedhar et al. ${ }^{8}$ reported the synthesis of a functionalized low molecular weight aromatic polyamide, viz., amino-terminated oligomer of poly(phenyleneterephthalamide) and its block copolymer with carboxyl terminated polybutadiene employing this reaction.

Metal chelate polymers are becoming increasingly important for producing materials of high thermal stability. Various Schiff's bases involving aldehydes and aromatic diamines have been extensively studied and critically reviewed..$^{9-13}$ Recently, we reported the synthesis and characterization of polyaramid-Schiff's base coordination polymers, using amino group terminated poly(methylenediphenyleneterephthalamide) and metal complexes of salicylaldehyde and 2-hydroxy-1-napthaldehyde. ${ }^{14}$ This article reports the synthesis, characterization and thermal analysis of Schiff's base coordination polymers of amino terminated poly(sulphoneterephthalamide) with $\mathrm{Co}(\mathrm{II}), \mathrm{Ni}(\mathrm{II})$, and $\mathrm{Cu}(\mathrm{II})$ complexes of salicylaldehyde and 2-hydroxy-1-napthaldehyde.

\section{EXPERIMENTAL}

\section{Materials}

All the materials used were of analytical grade. 4,4'Diaminodiphenylsulphone (E. Merck), terephthalic acid (TPA) (E. Merck), salicylaldehyde (S. Merck), triphenylphosphite (TPP) (Wilson Chemicals, India), and acetates of $\mathrm{Co}(\mathrm{II}), \mathrm{Ni}(\mathrm{II})$, and $\mathrm{Cu}$ (II) (all E. Merck) were used without further purification. Dimethylformamide (DMF), dimethylsulfoxide (DMSO), and pyridine (Qualigen, India) were distilled before use.

\section{Preparation of Poly(sulphonediphenyleneterephthalamide)}

The oligomer of PSDTA was prepared by phosphorylation. In a typical experiment, terephthalic acid (16.62 $\mathrm{g}, 0.1 \mathrm{M}$ ) was dissolved in a mixture of $200 \mathrm{~mL}$ DMF and $40 \mathrm{~mL}$ pyridine followed by the addition of Triphenylphosphite $(62 \mathrm{~g}, 0.2 \mathrm{M})$. The reaction mixture was brought to a constant temperature of $80 \pm 0.2^{\circ} \mathrm{C}$ in an oil bath and stirred continuously. 4,4'-Diaminodiphenylsulphone $(25.92 \mathrm{~g}, 0.12 \mathrm{M})$ was then slowly added. Heating was continued for $1.5 \mathrm{~h}$ at $80^{\circ} \mathrm{C}$ under nitrogen atmosphere with stirring. The mixture was poured in excess distilled methanol to precipitate the amino terminated aramid, PSDTA. The product was filtered, washed repeatedly with methanol and dried at $80^{\circ} \mathrm{C}$. Yield of the polymer was $60-70 \%$. The weight average molecular mass $\left(M_{w}\right)$ of the polyaramid was calculated viscometrically to be 3056 .

$$
\begin{aligned}
& \mathrm{HOOC}-\mathrm{C}_{6} \mathrm{H}_{4}-\mathrm{COOH}+\mathrm{H}_{2} \mathrm{~N}-\mathrm{C}_{6} \mathrm{H}_{4}-\mathrm{SO}_{2}-\mathrm{C}_{6} \mathrm{H}_{4}-
\end{aligned}
$$

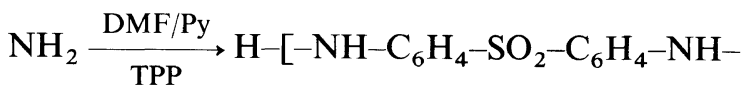

$$
\begin{aligned}
& \left.\mathrm{CO}-\mathrm{C}_{6} \mathrm{H}_{4}-\mathrm{CO}-\right]-\mathrm{NH}-\mathrm{C}_{6} \mathrm{H}_{4}-\mathrm{SO}_{2}-\mathrm{C}_{6} \mathrm{H}_{4}-\mathrm{NH}_{2} \text { (I) } \\
& \text { or } \mathrm{NH}_{2}-\mathrm{R}-\mathrm{NH}_{2}
\end{aligned}
$$


Preparation of Metal-Aldehyde Complexes

The salicylaldehyde and 2-hydroxy-1-napthaldehyde complexes of cobalt(II), nickel(II), and copper(II) were prepared by mixing aqueous solutions of metal acetates with ethanolic solutions of the aldehydes at 1:2 molar ratios. The reaction mixture was refluxed with continuous stirring for $2-3$ hours. The complexes which separated as solid colored materials were filtered, washed with ethanol followed by ether and then dried in an oven at $60^{\circ} \mathrm{C}$. The complexes were characterized by IR spectroscopy and elemental analysis.

$$
\begin{aligned}
& \mathrm{R}^{\prime} \text { - } \mathrm{OH} \\
& \sum_{\mathrm{HC}}^{\mathrm{R}}=\mathrm{O}+\mathrm{M}\left(\mathrm{CH}_{3} \mathrm{COO}\right)_{2} \\
& \stackrel{\text { EtOH } / \mathrm{H}_{2} \mathrm{O}}{\operatorname{Reflux}} \underset{\mathrm{HC}}{\mathrm{R}^{\prime}}=0 \pi^{\mathrm{M}^{\prime}} \mathrm{O}-\mathrm{R}^{\prime}
\end{aligned}
$$

Where, $\mathrm{M}=\mathrm{Co}(\mathrm{II}), \mathrm{Ni}(\mathrm{II})$, or $\mathrm{Cu}(\mathrm{II})$, and

$$
\mathrm{R}^{\prime}=o-\mathrm{C}_{6} \mathrm{H}_{4}-\text { or } 1,2-\mathrm{C}_{10} \mathrm{H}_{6}-
$$

\section{Synthesis of Coordination Polymers}

Equimolar solutions of poly(sulphonediphenyleneterephthalamide) (PSDTA) and respective metalaldehyde complexes in $50 \mathrm{~mL}$, hot DMF were refluxed for $6-8$ hours to obtain solid coordination polymers. The precipitates were filtered, washed repeatedly with hot DMF and alcohol and then dried. The coordination polymers were colored, powdery solids, insoluble in water, and common organic solvents. The reaction scheme for the synthesis of coordination polymers is given in Figure 1.

\section{RESULTS AND DISCUSSION}

\section{Composition}

The molecular weight $\left(M_{w}\right)$ of the ligand PSDTA was found to be 3056 . The calculated weight of repeat unit of the ligand was 378 . The weight of the terminal unit was 248. We included one water molecule per amide group in our calculations because aramids with moderately high molecular weight exhibit a strong tendency for water absorption. ${ }^{14}$ Therefore, for calculation of theoretical values of percentage of $\mathrm{C}, \mathrm{H}, \mathrm{N}$, and metal we employed the following as the molecular formula of the oligomer.

$$
\begin{gathered}
\mathrm{H}-\left[-\mathrm{NH}-\mathrm{C}_{6} \mathrm{H}_{4}-\mathrm{SO}_{2}-\mathrm{C}_{6} \mathrm{H}_{4}-\mathrm{NHCO}-\left(\mathrm{H}_{2} \mathrm{O}\right)-\right. \\
\left.\mathrm{C}_{6} \mathrm{H}_{4}-\mathrm{CO}-\mathrm{NH}-\right]_{7}-\mathrm{C}_{6} \mathrm{H}_{4}-\mathrm{SO}_{2}-\mathrm{C}_{6} \mathrm{H}_{4}-\mathrm{NH}_{2}
\end{gathered}
$$

The calculation of molecular weight for the amino

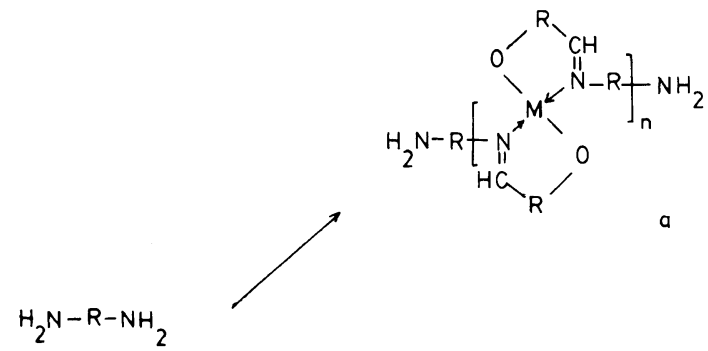

\begin{tabular}{|c|c|c|c|c|c|}
\hline \multirow{2}{*}{ No. } & \multirow{2}{*}{ Compounds } & \multicolumn{4}{|c|}{ Elemental analysis $^{\mathrm{a}}$} \\
\hline & & $\% \mathrm{C}$ & $\% \mathrm{H}$ & $\% \mathrm{~N}$ & $\% \mathrm{M}$ \\
\hline \multirow[t]{2}{*}{1.} & PSDTA & 60.4 & 3.9 & 7.99 & - \\
\hline & $\mathrm{C}_{152} \mathrm{H}_{110} \mathrm{~N}_{16} \mathrm{O}_{30} \mathrm{~S}_{8} \cdot 7 \mathrm{H}_{2} \mathrm{O}$ & 61.0 & 4.1 & 7.42 & - \\
\hline \multirow[t]{2}{*}{2.} & PSDTA-Co(II)-Sal' & 61.2 & 3.50 & 6.98 & 2.0 \\
\hline & $\begin{array}{l}\left(\mathrm{C}_{152} \mathrm{H}_{110} \mathrm{~N}_{16} \mathrm{O}_{30} \mathrm{~S}_{8} \cdot 7 \mathrm{H}_{2} \mathrm{O}\right)_{5} \\
\left(\mathrm{Co}(\mathrm{III}) \mathrm{C}_{14} \mathrm{H}_{10} \mathrm{O}_{2}\right)_{6}\end{array}$ & 60.6 & 4.07 & 6.70 & 2.1 \\
\hline \multirow[t]{2}{*}{3.} & PSDTA-Ni(II)-Sal' & 61.4 & 3.77 & 6.87 & 2.1 \\
\hline & $\begin{array}{l}\left(\mathrm{C}_{152} \mathrm{H}_{110} \mathrm{~N}_{16} \mathrm{O}_{30} \mathrm{~S}_{8} \cdot 7 \mathrm{H}_{2} \mathrm{O}\right)_{5} \\
\left(\mathrm{Ni}(\mathrm{II}) \mathrm{C}_{14} \mathrm{H}_{10} \mathrm{O}_{2}\right)_{6}\end{array}$ & 60.6 & 4.07 & 6.70 & 2.1 \\
\hline \multirow[t]{2}{*}{4.} & PSDTA-Cu(II)-Sal' & 60.0 & 3.66 & 6.50 & 2.3 \\
\hline & $\begin{array}{l}\left(\mathrm{C}_{152} \mathrm{H}_{110} \mathrm{~N}_{16} \mathrm{O}_{30} \mathrm{~S}_{8} \cdot 7 \mathrm{H}_{2} \mathrm{O}\right)_{5} \\
\left(\mathrm{Cu}(\mathrm{II}) \mathrm{C}_{14} \mathrm{H}_{10} \mathrm{O}_{2}\right)_{6}\end{array}$ & 60.5 & 4.06 & 6.69 & 2.3 \\
\hline \multirow[t]{2}{*}{5.} & PSDTA-Co(II)-Naphthal' & 62.0 & 2.96 & 7.20 & 2.0 \\
\hline & $\begin{array}{l}\left(\mathrm{C}_{152} \mathrm{H}_{110} \mathrm{~N}_{16} \mathrm{O}_{30} \mathrm{~S}_{8} \cdot 7 \mathrm{H}_{2} \mathrm{O}\right)_{4} \\
\left(\mathrm{Co}(\mathrm{III}) \mathrm{C}_{14} \mathrm{H}_{10} \mathrm{O}_{2}\right)_{5}\end{array}$ & 61.9 & 4.06 & 6.43 & 2.1 \\
\hline \multirow[t]{2}{*}{6.} & PSDTA-Ni(II)-Naphthal' & 62.0 & 3.54 & 6.99 & 2.0 \\
\hline & $\begin{array}{l}\left(\mathrm{C}_{152} \mathrm{H}_{110} \mathrm{~N}_{16} \mathrm{O}_{30} \mathrm{~S}_{8} \cdot 7 \mathrm{H}_{2} \mathrm{O}\right)_{4} \\
\left(\mathrm{Ni}(\mathrm{III}) \mathrm{C}_{14} \mathrm{H}_{10} \mathrm{O}_{2}\right)_{5}\end{array}$ & 61.9 & 4.06 & 6.43 & 2.1 \\
\hline \multirow[t]{2}{*}{7.} & PSDTA-Cu(II)-Naphthal' & 61.2 & 3.24 & 6.96 & 2.2 \\
\hline & $\begin{array}{l}\left(\mathrm{C}_{152} \mathrm{H}_{110} \mathrm{~N}_{16} \mathrm{O}_{30} \mathrm{~S}_{8} \cdot 7 \mathrm{H}_{2} \mathrm{O}\right)_{4} \\
\left(\mathrm{Cu}(\mathrm{III}) \mathrm{C}_{14} \mathrm{H}_{10} \mathrm{O}_{2}\right)_{5}\end{array}$ & 61.8 & 4.06 & 6.42 & 2.3 \\
\hline
\end{tabular}
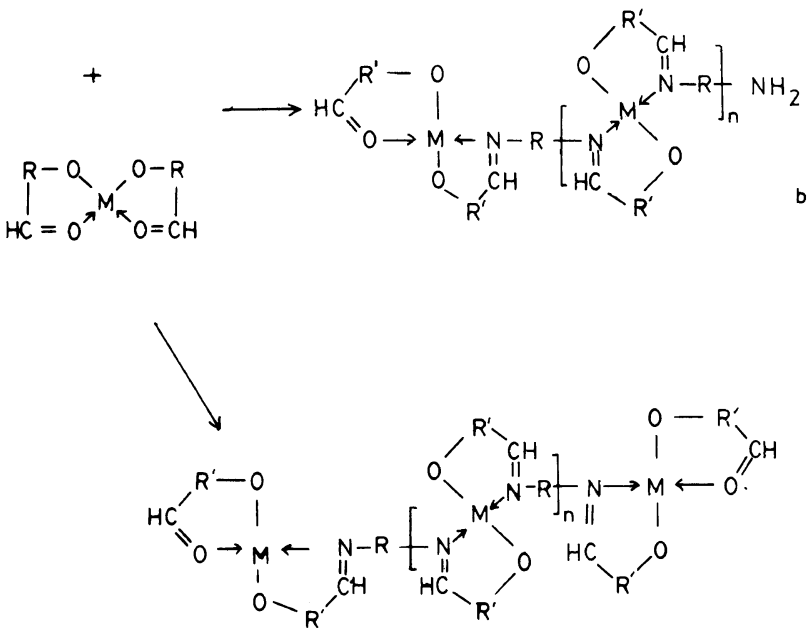

Figure 1. Reaction scheme for the Synthesis of Coordination Polymers.

Table I. Analytical data of PSDTA and metal complexes

\footnotetext{
${ }^{a}$ In every case upper values represent observed results and lower values represent the theoretically calculated values.
} 
Table II. Important IR spectral assignments of PSDTA and metal complexes ${ }^{\mathrm{a}}$

\begin{tabular}{|c|c|c|c|c|c|c|c|}
\hline \multirow{2}{*}{$\begin{array}{c}\text { Assignments } \\
\mathrm{cm}^{-1}\end{array}$} & \multirow[b]{2}{*}{ PSDTA } & \multicolumn{6}{|c|}{ Compounds } \\
\hline & & \multicolumn{6}{|c|}{ PSDTA coordination polymers } \\
\hline $\mathrm{NH}$ & $3350 \mathrm{~s}$ & $3350 \mathrm{~s}$ & $3350 \mathrm{~s}$ & $3350 \mathrm{~s}$ & $3350 \mathrm{~s}$ & $3350 \mathrm{~s}$ & $3350 \mathrm{~s}$ \\
\hline $\mathrm{Ar}-\mathrm{CH}$ & $3060 \mathrm{~m}$ & $3020 \mathrm{~m}$ & $3040 \mathrm{~m}$ & $3060 \mathrm{~m}$ & $3040 \mathrm{w}$ & $3020 \mathrm{w}$ & $3040 \mathrm{~m}$ \\
\hline Amide I & $1690 s$ & $1690 \mathrm{~s}$ & $1690 \mathrm{~s}$ & $1695 \mathrm{~s}$ & $1695 \mathrm{~s}$ & $1700 s$ & $1690 \mathrm{~s}$ \\
\hline Aromatic skeleton & $1590 \mathrm{~m}$ & $1600 s$ & $1590 \mathrm{~s}$ & $1595 \mathrm{~s}$ & $1600 \mathrm{~s}$ & $1600 \mathrm{~s}$ & $1600 \mathrm{~s}$ \\
\hline Amide II & $1540 \mathrm{~s}$ & $1540 \mathrm{~s}$ & $1530 \mathrm{~s}$ & $1540 \mathrm{~s}$ & $1540 \mathrm{~s}$ & $1540 \mathrm{~s}$ & $1540 \mathrm{~s}$ \\
\hline $\mathrm{C}=\mathrm{N}$ & - & $1560 \mathrm{~s}$ & $1570 \mathrm{~s}$ & $1560 \mathrm{~s}$ & $1550 \mathrm{~s}$ & $1570 \mathrm{~s}$ & $1575 \mathrm{~s}$ \\
\hline Amide III & $1285 \mathrm{~s}$ & $1290 \mathrm{~s}$ & $1285 \mathrm{~s}$ & $1290 \mathrm{~s}$ & $1290 \mathrm{~s}$ & $1285 \mathrm{~s}$ & $1290 \mathrm{~s}$ \\
\hline $\mathrm{SO}_{2}$ (asym) & $1320 \mathrm{~s}$ & $1325 \mathrm{~s}$ & $1325 \mathrm{~s}$ & $1330 \mathrm{~s}$ & $1320 \mathrm{~s}$ & $1320 \mathrm{~s}$ & $1330 \mathrm{~s}$ \\
\hline $\mathrm{SO}_{2}$ (sym) & $1110 \mathrm{~s}$ & $1115 \mathrm{~s}$ & $1110 \mathrm{~s}$ & $1115 \mathrm{~s}$ & $1110 \mathrm{~s}$ & $1115 \mathrm{~s}$ & $1110 \mathrm{~s}$ \\
\hline $\begin{array}{l}p \text {-Substituted benzene } \\
\text { vibration }\end{array}$ & $830 \mathrm{~m}$ & $825 \mathrm{~s}$ & $830 \mathrm{~s}$ & $825 \mathrm{~s}$ & $840 \mathrm{~m}$ & $830 \mathrm{~s}$ & $825 \mathrm{~s}$ \\
\hline $\mathrm{M}-\mathrm{O}$ & - & $600 \mathrm{~s}$ & $585 \mathrm{~m}$ & $580 \mathrm{~m}$ & $590 \mathrm{~s}$ & $600 \mathrm{~m}$ & $580 \mathrm{~s}$ \\
\hline $\mathrm{M}-\mathrm{N}$ & - & $400 \mathrm{~s}$ & $410 \mathrm{~s}$ & $430 \mathrm{~m}$ & $400 \mathrm{~s}$ & $415 \mathrm{~m}$ & $410 \mathrm{~m}$ \\
\hline
\end{tabular}

${ }^{\mathrm{a}} \mathrm{s}=$ strong; $\mathrm{m}=$ medium; $\mathrm{w}=$ weak $; \mathrm{br}=$ broad .

terminated ligand by use of this formula, gives the value 3020 , which is appreciably close to the experimental value.

The observed values of elemental analysis and theoretical calculations are depicted in Table I. Deviations from the theoretical values in case of ligand PSDTA may be due to the polymeric nature of the aramid. It is very well possible that the polydispersity of the ligand is not in a narrow range. Similarly for Schiff's base metal complexes, the stoichiometry may not be uniform. The terminal units may have variable compositions viz., structures $\mathrm{a}, \mathrm{b}$, or $\mathrm{c}$ as given in the Figure 1. For theoretical calculations, we used structure c. The experimental values of the elemental analysis showed the best agreement with the theoretical values when we consider the ratio of ligand and the metal-aldehyde complexes as $5: 6$ for metal-salicylaldehyde and as $4: 5$ for the metalnapthaldehyde complexes. However, the deviations from the theoretical calculations are quite significant, attributed again to the polymeric nature of coordination polymers. All the structural possibilities of the end units are given in Figure 1. Some other combinations are also possible. Further, the possibility of structural defects can not be ruled out.

\section{IR Spectral Studies}

The infrared group frequencies of diagnostic importance are showed in Table II. The spectra of the metal coordination polymers of PSDTA were compared with the spectrum of the ligand. The strong band observed at $3350 \mathrm{~cm}^{-1}$ may be attributed to $\mathrm{NH}$ stretching vibrations of amide group of PSDTA, this band is not affected on coordination. Following coordination an additional band appeared in the region of $1550-1545 \mathrm{~cm}^{-1}$ along with amide II band at $1530 \mathrm{~cm}^{-1}$, which can be attributed to the creation of the $\mathrm{C}=\mathrm{N}$ group as a result of Schiff's base formation. Generally this absorption appeared in the range $1690-1590 \mathrm{~cm}^{-1}$. The appearance of this band in the lower range suggests involvement of azomethine nitrogen in coordination (i.e., $\mathrm{C}=\mathrm{N} \rightarrow \mathrm{M}$ ). This observation supports the coordination through the terminal amino groups of the ligand PSDTA. The other
Table III. Magnetic moments of PSDTA-metal complexes

\begin{tabular}{lcc}
\multicolumn{1}{c}{ Compounds } & $\mu_{\text {eff }}$ B.M. & Geometry proposed \\
\hline PSDTA-Co(II)-Sal' & 4.48 & Tetrahedral \\
PSDTA-Ni(II)-Sal' & 4.36 & Tetrahedral \\
PSDTA-Cu(II)-Sal' & Diamagnetic & Square planar \\
PSDTA-Co(II)-Naphthal' & Diamagnetic & Square planar \\
PSDTA-Ni(II)-Naphthal' & 1.69 & Square planar \\
PSDTA-Cu(II)-Naphthal' & 1.82 & Square planar \\
\hline
\end{tabular}

bands of the ligand PSDTA, viz. amide I at $1630 \mathrm{~cm}^{-1}$, amide II at $1530 \mathrm{~cm}^{-1}$, and amide III at $1290 \mathrm{~cm}^{-1}$ showed no appreciable change on coordination and therefore it is evident that the amide group does not participate in coordination.

The appearance of $\mathrm{M}-\mathrm{O}$ bonds in the region 530$495 \mathrm{~cm}^{-1}$ and $\mathrm{M}-\mathrm{N}$ bands in the region $430-400 \mathrm{~cm}^{-1}$ further confirmed the participation of terminal amino groups as well as nitrogen and oxygen in coordination.

\section{Magnetic Susceptibility Measurements}

The magnetic moments of different PSDTA-metal coordination polymers are summarized in Table III. The magnetic moments in the range 4.36-4.69 B.M. for PSDTA-Co(II) coordination polymers are consistent with tetrahedral geometry. PSDTA-Ni(II) coordination polymers showed diamagentic behavior, indicating their square planar geometry. PSDTA-Cu(II) coordination polymers showed magnetic moments in the range 1.65 1.85 B.M., as the expected for square planar $\mathrm{Cu}$ (II) complexes.

\section{Thermogravimetric Analysis}

TG analysis of PSDTA ligand was done in several runs and the results showed variations. This may be due to different amounts of water adsorbed by the aramid samples used for TGA. Generally 1.5 water molecules are firmly bound per amide group and besides this capillary condensation is also possible. ${ }^{15}$ To overcome the problem of variable results in TGA the samples were heated to $105^{\circ} \mathrm{C}$ for 6 hours and cooled in a vacuum desiccator. 


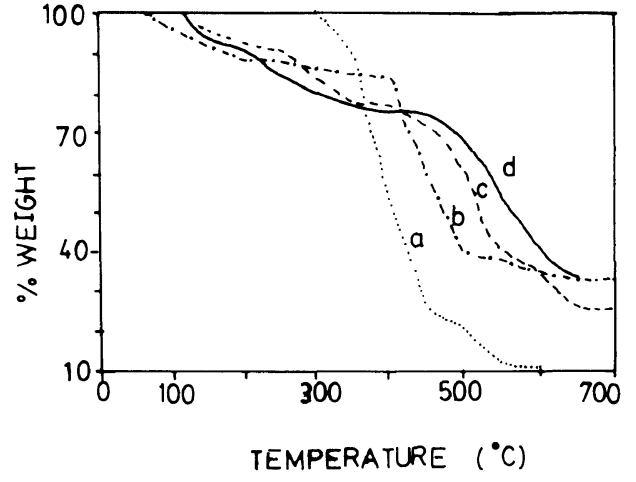

Figure 2. TGA curves: (a) PSDTA; (b) PSDTA-Co(II)-Sal'; (c) PSDTA-Ni(II)-Sal'; (d) PSDTA-Cu(II)-Sal'.

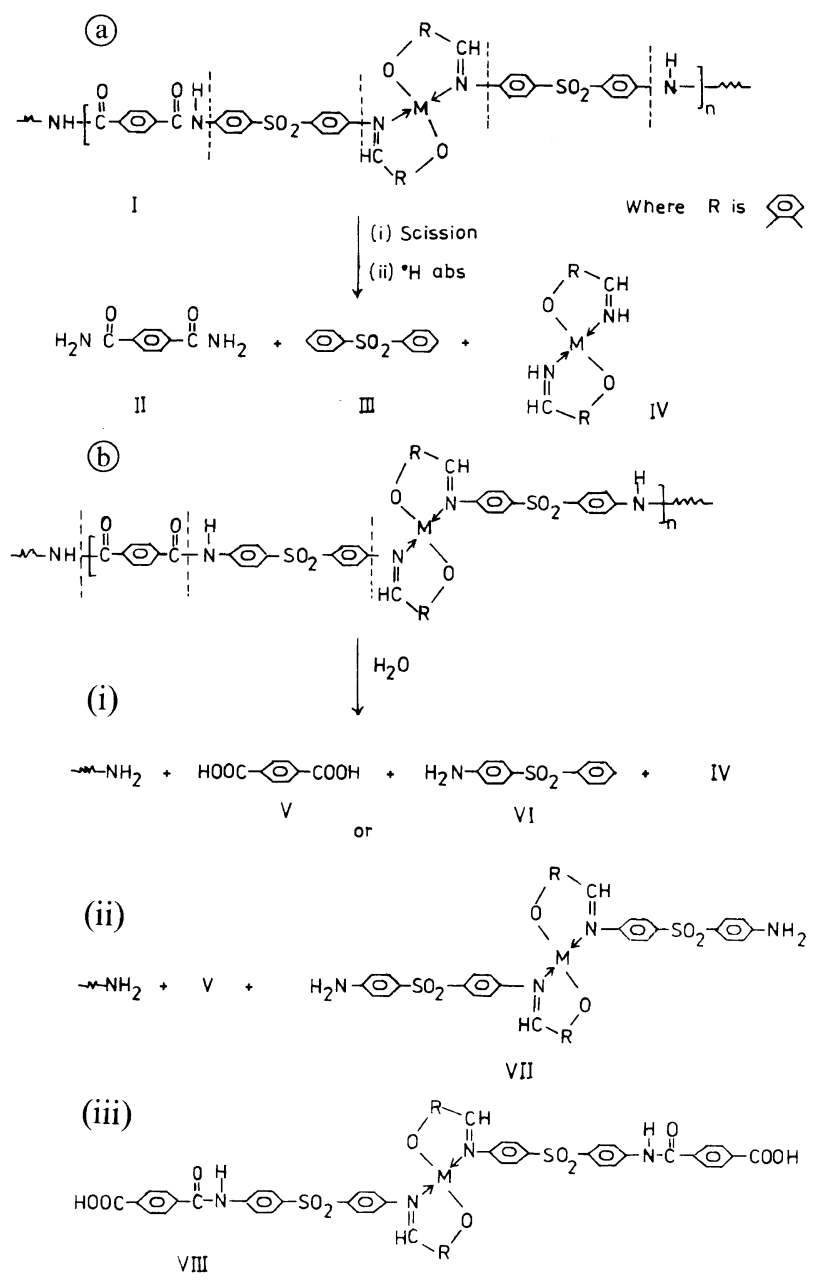

Figure 3. Degradation mechanism of coordination polymers.

TGA studies to determine the stability of aromatic polyamides based on terephthaloylchloride and 4,4'-diaminodiphenylsulphone show that the aramid loses only $2.8 \%$ of its weight in air at $300^{\circ} \mathrm{C}$ after 2 hours. ${ }^{16}$

It is apparent from Figure 2 that the oligomeric ligand PSDTA exhibits weight loss only above $300^{\circ} \mathrm{C}$ and then rapidly looses weight and volatilises completely at $700^{\circ} \mathrm{C}$. The coordination polymers were not preheated and thus started decomposing just above $100^{\circ} \mathrm{C}$. The initial weight loss may be due to absorbed moisture as the IR spectra do not show presence of coordinated water. The observed weight loss in the $100-150^{\circ} \mathrm{C}$ range showed corre-
Table IV. Thermogravimetric data of PSDTA and metal complexes

\begin{tabular}{rrrrr}
\hline & \multicolumn{4}{c}{ Percentage weight loss } \\
\cline { 2 - 5 } Temp ${ }^{\circ} \mathrm{C}$ & PSDTA & $\begin{array}{c}\text { PSDTA } \\
\text { Cu(II)-Sal }\end{array}$ & $\begin{array}{c}\text { PSDTA } \\
\text { Co(II)-Sal }\end{array}$ & $\begin{array}{r}\text { PSDTA } \\
\text { Ni(II)-Sal' }\end{array}$ \\
\hline 0 & 0.0 & 0.0 & 0.0 & 0.0 \\
50 & 0.0 & 0.0 & 0.0 & 0.0 \\
100 & 0.0 & 0.0 & 1.0 & 5.0 \\
150 & 0.0 & 7.0 & 5.0 & 8.0 \\
200 & 0.0 & 10.0 & 7.0 & 10.0 \\
250 & 0.0 & 15.0 & 8.5 & 11.0 \\
300 & 0.0 & 20.0 & 14.0 & 13.0 \\
350 & 11.0 & 23.0 & 20.0 & 14.0 \\
400 & 47.0 & 25.0 & 21.0 & 15.0 \\
450 & 75.0 & 25.0 & 25.0 & 37.0 \\
500 & 80.0 & 32.0 & 35.0 & 63.0 \\
550 & 89.0 & 46.0 & 60.0 & 64.5 \\
600 & 90.0 & 61.0 & 67.0 & 67.0 \\
650 & 90.0 & 67.0 & 75.0 & 68.0 \\
\hline
\end{tabular}

spondence with the calculated values for loss of water molecules. The loss of water in this temperature range further suggests absence of water molecules in coordination sphere. Table IV and Figure 2 indicate coodination polymers to have more thermal stability than the ligand and not to decompose completely even at $700^{\circ} \mathrm{C}$.

\section{Degradation Mechanism}

Degradation of polymers is usually complex and rarely occurs by a single mechanism. However, a tentative degradation mechanism can be proposed on the basis of thermogravimetric analytical data. The degradation mechanism is shown in the Figure 3. From Table IV it is apparent that the residual weights are $34 \%, 25 \%$, and $32 \%$ for coordination polymers from $\mathrm{Cu}(\mathrm{II}), \mathrm{Co}(\mathrm{II})$, and $\mathrm{Ni}(\mathrm{II})$, respectively. The percentage of metal ion is nearly $2 \%$ in all cases. Therefore the residue may not be the metal or metal oxide only, but also an organic fraction. The percentage weight corresponding to the cyclic structure formed by chelation through Schiff's base structure was $9.6 \%$. The residue may thus have additional fractions attached to the chelate ring. The percentage weight corresponding to the fraction VII was $23.58 \%$. Therefore, for cobalt II coordination polymers, there may be large contribution of structure VII to residual weight. Residual weights in case of $\mathrm{Cu}(\mathrm{II})$ and $\mathrm{Ni}$ (II) complexes are higher than $\mathrm{Co}(\mathrm{II})$ complexes. Percentage weights corresponding to VIII for Ni(II) and $\mathrm{Cu}(\mathrm{II})$ complexes were $\sim 29.34 \%$ and $29.43 \%$, respectively.

\section{REFERENCES}

1. N. Yamazaki, F. Higashi, and J. Kawabata, J. Polym. Sci., Polym. Chem. Ed., 12, 2149 (1974).

2. N. Yamazaki and F. Higashi, J. Polym. Sci., Polym. Lett. Ed., 12, 185 (1974).

3. N. Yamazaki, M. Matsumoto, and F. Higashi, J. Polym. Sci., Polym. Chem. Ed., 13, 1373 (1975).

4. N. Yamazaki and F. Higashi, Tetrahedron, 30, 1323 (1974).

5. W. R. Krigbaum, R. Kotak, Y. Mihara, and J. Preston, J. Polym. Sci., Polym. Chem. Ed., 22, 4045 (1984).

6. F. Higashi, S. Ogata, and V. Aoki, J. Polym. Sci., Polym. Chem. $E d ., 20,2081$ (1982). 


\section{A. BAJPAI, S. RAI, and U. D. N. BAJPAI}

7. S. Ogata, M. Kakimoto, and Y. Imai, Macromolecules, 18, 851 (1985).

8. J. Sreedhar, S. Rai, S. K. Nema, P. V. Prabhakaran, and K. V. C. Rao, J. Polym. Sci., Part C, Polym. Lett., 26, 493 (1988).

9. J. H. Hodgkin and J. Heller, J. Polym. Sci., 37 (1970).

10. B. F. G. Johnson, Special Periodical Reports-Inorganic Chemistry of Transition Elements, 1, 197 (1972).

11. Y. Maeda, S. Shite, Y. Takashima, and Y. Nishida, Bull. Chem. Soc. Jpn., 50, 2902 (1977).
12. C. A. McAuliffe, F. P. McCullough, M. J. Parrott, C. A. Rice, and B. J. Sayle, J. Chem. Soc., 1762 (1977).

13. S. N. Poddar and N. Saha, Indian J. Appl. Chem., 33, 244 (1970)

14. U. D. N. Bajpai, S. Rai, and A. Bajpai, J. Appl. Polym. Sci., 48, 1241 (1993).

15. Y. P. Khanna and E. M. Pearce, J. Polym. Sci., Polym. Chem. Ed., 19, 2799 (1981).

16. C. Arnold, Jr., J. Polym. Sci., Macromol. Rev., 14, 265 (1979). 